\title{
The Impact of Breast Care Nurses on Patients' Satisfaction, Understanding of the Disease, and Adherence to Adjuvant Endocrine Therapy
}

\author{
Ute-Susann Albert Cosima Zemlin Peymann Hadji Volker Ziller \\ Barbara Kuhler Birgit Frank-Hahn Uwe Wagner Matthias Kalder
}

Klinik für Gynäkologie, Gynäkologische Endokrinologie und Onkologie, Universitätsklinikum Giessen und Marburg, Germany

\section{Keywords}

Breast cancer - Breast care nurse - Quality of life . Treatment adherence $\cdot$ Patient satisfaction

\section{Summary}

Background: Breast care nurses (BCNs) are specialized caregivers in certified breast cancer center teams. The impact of a BCN's work remains unknown. Patients and Methods: The role of $\mathrm{BCN}$ care was evaluated in a post-discharge mail survey of 360 patients. Results: A total of 207 (87\%) of 237 (66\%) returned questionnaires were analyzed; 171 (83\%) patients had BCN contact, $36(17 \%)$ did not. The mean global quality of life scores (EORTC-QLQ-C30) were 66.3 for women with contact to a BCN versus 62.5 for women without such contact $(p<0.05)$. Women with a BCN contact had better results than women without ( $p<0.001)$ for the following parameters: receipt of information material (84 vs. 64\%), information about hospital procedures (93 vs. $72 \%$ ) and treatment plan (91 vs. 63\%), and knowledge of own tumor hormone receptor status ( 83 vs. $53 \%$ ). Medication adherence correlated with the knowledge about the tumor hormone receptor status and was significantly higher in women having contact with a BCN (79 vs. 56\%). The high recommendation rate $(81 \%)$ reflects the high level of satisfaction with BCNs. A qualitative analysis of comments and suggestions identified aspects to improve BCN services. Conclusions: BCN improve satisfaction and treatment adherence in breast cancer patients.

\section{Schlüsselwörter \\ Brustkrebs · Breast Care Nurse · Lebensqualität . \\ Behandlungsadhärenz $\cdot$ Patientenzufriedenheit}

\section{Zusammenfassung}

Hintergrund: Breast Care Nurses (BCNs) sind spezialisierte Pflegekräfte im multidisziplinären Team zertifizierter Brustkrebszentren. Der Einfluss der Arbeit von $\mathrm{BCNs}$ ist bisher unbekannt. Patienten und Methoden: Eine poststationäre Befragungsstudie von 360 Patientinnen wurde zur Rolle der BCN-Betreuung durchgeführt. Ergebnisse: Von 237 (66\%) zurückgesendeten Fragebögen wurden 207 (87\%) in die Analyse eingeschlossen; 171 (83\%) Patientinnen gaben einen Kontakt zur BCN an, $36(17 \%)$ keinen. Die mittleren Scorewerte zur globalen Lebensqualität (EORTC-QLQ-C30) ergaben für Frauen mit Kontakt zu einer BCN 66,3 und für Frauen ohne BCNKontakt 62,5 ( $p<0,05$ ). Frauen mit BCN-Kontakt wiesen gegenüber Frauen ohne BCN-Kontakt hinsichtlich folgender Parameter bessere Ergebnisse auf $(p<0,001)$ : Erhalt von Informationsmaterialien (84 verus $64 \%$ ), Informationen zu organisatorischen Abläufen (93 versus $72 \%$ ) und zum Behandlungsplan (91 versus 63\%) sowie Kenntnisstand des eigenen Tumorhormonrezeptorstatus (83 versus 53\%). Die Medikamenteneinnahme korreliert mit dem Wissen zum eigenen Tumorhormonrezeptorstatus und erfolgte signifikant häufiger bei Frauen mit BCNKontakt (79 versus 56\%). Die hohe Zufriedenheit der Patientinnen (96\%) mit dem BCN-Gespräch spiegelt sich auch im Empfehlungsverhalten (81\%) wider. Die qualitative Analyse von Mitteilungen und Anregungen ergab Hinweise zur Verbesserung der BCN-Betreuung. Schlussfolgerungen: $\mathrm{BCN}$ s verbessern die Zufriedenheit und das Medikamenteneinahmeverhalten von Patientinnen mit Brustkrebs.
Prof. Dr. med. Ute-Susann Albert

Universitätsklinikum Giessen und Marburg

Klinik für Gynäkologie, Gynäkologische Endokrinologie und Onkologie, Brustzentrum Regio Baldingerstraße, 35043 Marburg, Germany

Tel. +49 6421 58664-32, Fax -07

albertu@med.uni-marburg.de 


\section{Introduction}

The standards set by the German Cancer Society (Deutsche Krebsgesellschaft, DKG) and the German Society for Senology (Deutsche Gesellschaft für Senologie, DGS) require to include specialized nursing professionals in interdisciplinary teams working at certified breast cancer centers [1]. Whereas the roles of oncology and clinical trials nurses are clearly defined and accepted, the role of breast care nurses (BCNs) in Germany remains unclear. The Board of the National Breast and Ovarian Cancer Centre (NBOCC, 2005), the European Society of Breast Cancer Specialists (EUSOMA, 2007), and the European Oncology Nursing Society (EONS, 2008) developed standards of competence that a BCN needs to meet. These organizations define 4 domains of competency: clinical practice, education, management, and research [2-4]. The following core areas of activity have been defined for BCNs: i) involvement in assessing the physical and psychosocial status of patients with breast cancer; ii) referral of patients to the respective services needed, support, and practical assistance; iii) provision of information, education, and counseling to breast cancer patients and their families; iv) membership in the multidisciplinary team of a breast cancer center, with the $\mathrm{BCN}$ playing a central role in coordinating treatment and delivery of care. Referring to these key working areas of a $\mathrm{BCN}$, the present study examines how women with breast cancer accepted and rated the care and counseling they received at a Breast Cancer Center. The main outcome measures were receipt of relevant information on hospital treatment procedures, personalized treatment plan, recommendations for follow-up care, and knowledge about the individual tumor hormone receptor status. Secondary outcome criteria consisted of an assessment of the experiences gained from conversations/ consultations with the $\mathrm{BCN}$, the recommendation behavior and, if applicable, adherence to adjuvant endocrine therapy.

\section{Patients and Methods}

\section{Survey}

We conducted a mail survey from February to April 2010 to analyze the experience of breast cancer patients with regard to the care and support given by specialist BCNs during their stay at the Breast Cancer Center (January to December 2009). Patients received a questionnaire together with a cover letter and a stamped reply envelope. The 2-page questionnaire comprised 15 sets of questions about 5 topics: i) Global quality of life (questions from the EORTC-QLQ-C30) - health status, quality of life; ii) Receipt of information - hospital treatment procedure, personal treatment plan, supply of healthcare products (bra/breast prosthesis), printed information material (special information brochure of the Breast Cancer Center about follow-up care); iii) Consultation with the $\mathrm{BCN}$ - general atmosphere, active participation in the conversation, satisfaction with care, recommendation behavior; iv) Knowledge of one's own disease - tumor hormone receptor status, medication use, medication adherence; v) Participation and wish to be contacted directly by the Breast Cancer Center - comments and suggestions, personal invitation to events organized for patients.

\section{Analysis of Data}

The definitions and formulas described by the American Association for Public Opinion Research (AAPOR) for 'Mail surveys of specifically named persons' were used to report final dispositions and calculations of outcome rates [5]. According to these definitions, a questionnaire was complete if the respondent had answered at least $80 \%$ of the questions or more. The questionnaire was partly completed if $50 \%$ or more of the questions had been answered, whereas questionnaires with less than $49 \%$ of the answers filled in were considered incomplete. The cooperation rate is the proportion of all cases interviewed of all eligible persons contacted. The response rate is the rate of complete and partially completed questionnaires divided by the number of eligible questionnaires. The data were subjected to a primarily descriptive statistical analysis. Univariate data analyses were employed to obtain frequency distributions, percentages, and mean values as well as 4-fold tables to describe correlated binary traits. To calculate the differences between groups, the chi-square test or the t-test were applied when needed. Global quality of life was expressed as a score computed from the responses to questions 29 and 30 in accordance with the scoring manual for the EORTC-QLQ-C30 [6]. A qualitative analysis was performed when comments and suggestions were given by respondents within the participation section of the questionnaire.

\section{Ethics}

The project was conducted as a scientific study in accordance with the 'Declaration for the Area of the Federal Republic of Germany on the ICC/ESOMAR International Code of Marketing and Social Research Practice' [7] and the guidelines of the local ethics committee of the Philipps-University Marburg.

\section{Results}

The questionnaires were mailed to 360 patients within a follow-up period of 2-14 months after their treatment in hospital in 2009 . The cooperation rate was $66 \%$. The response rate was $87 \%$ including a total of 207 questionnaires for study analysis. According to the criteria established by the AAPOR for mailed surveys of specifically named persons, the data quality with $90 \%$ completed questionnaires was high (fig. 1).
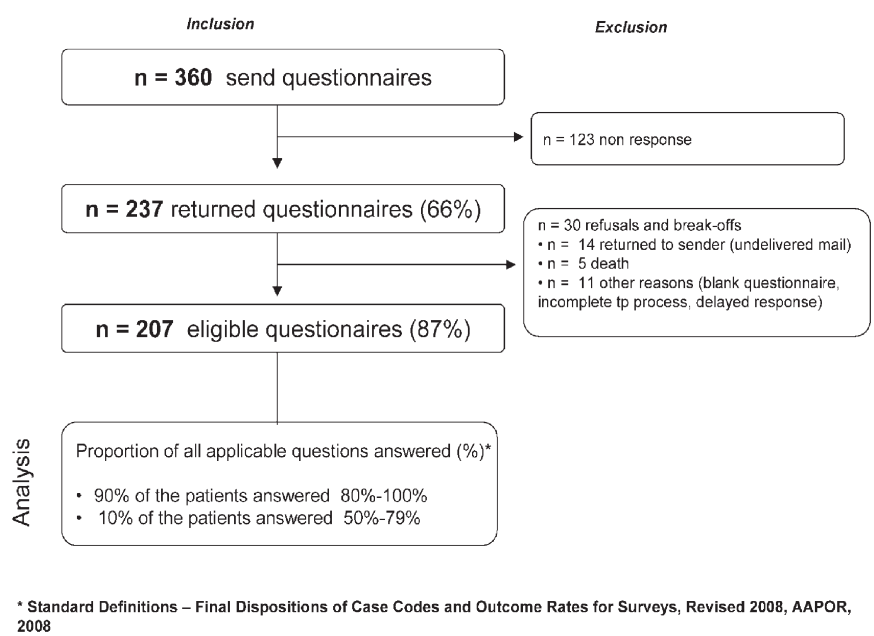

Fig. 1. Study design: data collection and analysis of outcome rates. 


\section{Characteristics of Survey Participants}

The patients' mean age was 60 years (range 31-95 years). A total of $171(83 \%)$ patients responded that they had been in contact with a BCN, $36(17 \%)$ patients did not recall any such contact. The mean age of patients having no contact with a BCN was 61 years (range $48-88$ years). Asked to rate their state of health and quality of life on a Likert scale of 1-7, more than $60 \%$ gave a score of good to excellent (score 5-7). The mean global quality of life score for women who were in contact with a $\mathrm{BCN}$ was 66.3 , whereas the score for women without any such contact was $62.5(\mathrm{p}<0.05)$ (fig. 2).

\section{BCN Consultation}

A total of $95 \%$ of the 171 patients who had consulted a BCN reported that they had been given the opportunity to discuss unclear issues and ask questions. The general atmosphere during the conversation was rated as very pleasant by $49 \%$ of these respondents, $42 \%$ considered the atmosphere pleasant, $9 \%$ neutral, and none of the women felt uncomfortable. Overall, $39 \%$ of the women were very satisfied with the conversation, $57 \%$ were satisfied, and $4 \%$ less satisfied. None of the patients were dissatisfied. This positive experience is reflected in the response to the question about their recommendation behavior. Asked whether they would recommend counseling and support by a $\mathrm{BCN}$ to other women in a similar situation, $81 \%$ checked 'yes, definitely' and 19\% marked 'perhaps' (table 1).

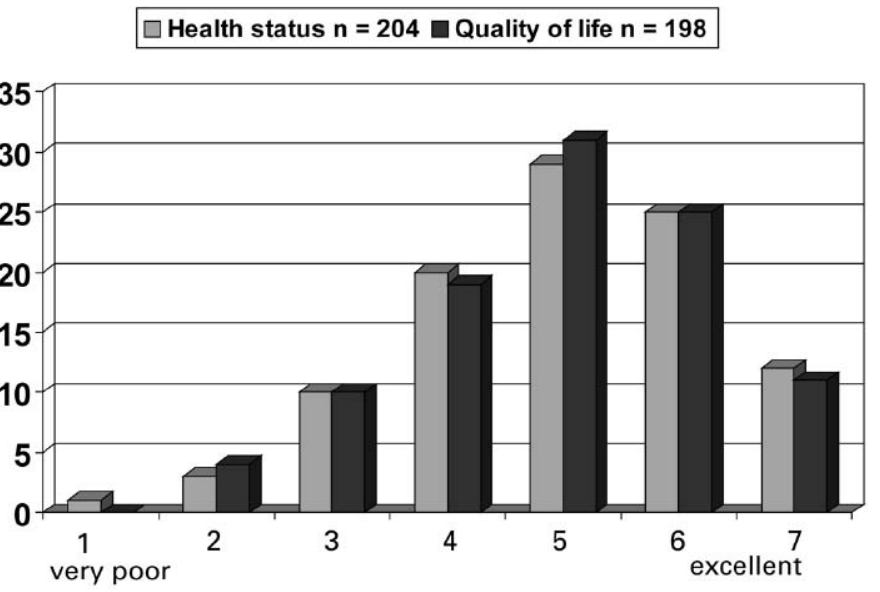

Fig. 2. Health status and quality of life (EORTC-QLQ-C30).
Results for Receipt of Information and Knowledge of One's Own Disease

As far as information about organizational procedures in the hospital is concerned, $88 \%$ of the respondents felt that the information provided was very good to good, $12 \%$ stated the information as inadequate or that they had not received any information at all; $86 \%$ of the women felt well-informed about their personal treatment plan, $81 \%$ had received a brochure including information on follow-up care, and $65 \%$ had been advised about a bra or breast prosthesis. The patients' knowledge of their own disease was assessed by asking about their own tumor hormone receptor status; $23 \%$ answered this question by replying 'don't know', 67\% reported it as positive, and $10 \%$ as negative.

Given that patients with and without contact to a $\mathrm{BCN}$ might have different experiences, the survey results were analyzed separately for the 2 groups: $72 \%$ of patients who were not in contact with a $\mathrm{BCN}$ were informed about organizational procedures and $64 \%$ were familiar with their treatment plan, whereas the figures for patients having contact with a $\mathrm{BCN}$ were $93 \%$ and $91 \%$, respectively; $64 \%$ of the women who had not been in touch with a $\mathrm{BCN}$ and $84 \%$ of the patients with contact had received information material on follow-up care; $53 \%$ of the patients without contact to a $\mathrm{BCN}$ knew their tumor hormone receptor status as opposed to $83 \%$ of the women with such a consultation. Thus, women who had been in contact with a BCN showed a significantly better level of information $(\mathrm{p}<0.001)$ (table 2$)$.

\section{Results for Medication Use and Knowledge \\ of One's Own Tumor Hormone Receptor Status}

A total of 149 patients responded to questions about endocrine therapy; $56 \%$ were taking tamoxifen and $44 \%$ aromatase inhibitors (23\% anastrozole, $18 \%$ letrozole, $3 \%$ exemestane); $57 \%$ out of 133 patients reported that they were taking their medication in the morning, as opposed to $43 \%$ who took their drugs in the evenings. Medication use and knowledge of one's own tumor hormone receptor status were evaluated separately for the 2 categories of patients, i.e. with or without contact to a $\mathrm{BCN}$. Medication adherence correlated with knowledge about one's personal tumor hormone receptor status: $56 \%$ of the women without any contact to a

Table 1. Perceived breast care nurse $(\mathrm{BCN})$ care

\begin{tabular}{|c|c|c|c|c|c|}
\hline \multirow[t]{2}{*}{ Questionnaire domain } & \multicolumn{5}{|c|}{ Patients, n (\%) } \\
\hline & total & $\begin{array}{l}\text { yes / very pleasant / } \\
\text { very satisfied / yes, } \\
\text { definitely }\end{array}$ & $\begin{array}{l}\text { - / pleasant / } \\
\text { satisfied / perhaps }\end{array}$ & $\begin{array}{l}-/ \text { neutral / } \\
\text { less satisfied / } \\
\text { not recommended }\end{array}$ & $\begin{array}{l}\text { no / unpleasant / } \\
\text { dissatisfied / - }\end{array}$ \\
\hline Active participation in the conversation & 171 & $162(95)$ & - & - & $9(5)$ \\
\hline Atmosphere during the consultation & 162 & $79(49)$ & $68(42)$ & $15(9)$ & $0(0)$ \\
\hline Satisfaction with BCN care & 171 & $67(39)$ & $97(57)$ & $7(4)$ & $0(0)$ \\
\hline
\end{tabular}


Table 2. Survey results regarding receipt of information, knowledge, and participation

\begin{tabular}{|c|c|c|c|c|c|}
\hline \multirow[t]{3}{*}{ Questionnaire domain } & \multicolumn{4}{|c|}{ Patients, n (\%) } & \multirow[t]{3}{*}{$\mathrm{p}$} \\
\hline & \multirow[t]{2}{*}{ total } & \multicolumn{3}{|c|}{ positive response } & \\
\hline & & total & without $\mathrm{BCN}$ & with $\mathrm{BCN}$ & \\
\hline $\begin{array}{l}\text { Provision of information } \\
\text { Hospital treatment procedures } \\
\text { Treatment plan } \\
\text { Brochure follow-up care } \\
\text { Supply of health care products (bra/prosthesis) }\end{array}$ & $\begin{array}{l}207 \\
205 \\
207 \\
183\end{array}$ & $\begin{array}{l}185(88) \\
177(86) \\
167(81) \\
119(65)\end{array}$ & $\begin{array}{l}26(72) \\
23(64) \\
23(64) \\
-\end{array}$ & $\begin{array}{l}159(93) \\
154(91) \\
144(84) \\
-\end{array}$ & $\begin{array}{l}<0.001 \\
\text { S } \\
\text { S } \\
\text { S } \\
\text { n.a. }\end{array}$ \\
\hline $\begin{array}{l}\text { Knowledge and compliance } \\
\text { Own tumor hormone receptor status } \\
\text { Compliance to medication and knowledge about tumor HR status }\end{array}$ & $\begin{array}{l}185 \\
149\end{array}$ & $\begin{array}{l}143(77) \\
111(74)\end{array}$ & $\begin{array}{l}19(53) \\
15(56)\end{array}$ & $\begin{array}{r}124(83) \\
96(79)\end{array}$ & $\begin{array}{l}\mathrm{S} \\
\mathrm{S}\end{array}$ \\
\hline $\begin{array}{l}\text { Participation } \\
\text { Comments and suggestions } \\
\text { Invitation to patient educational session }\end{array}$ & $\begin{array}{l}188 \\
180\end{array}$ & $\begin{array}{r}73(39) \\
123(68)\end{array}$ & $\begin{array}{l}- \\
-\end{array}$ & $\begin{array}{l}- \\
-\end{array}$ & $\begin{array}{l}\text { n.a. } \\
\text { n.a. }\end{array}$ \\
\hline
\end{tabular}

BCN took their medication versus $79 \%$ of women with contact to a BCN $(\mathrm{p}<0.001)$ (table 2$)$.

\section{Results for Participation and the Wish to Be Contacted Directly by the Breast Cancer Center}

A total of 73 patients offered comments and suggestions as requested in the questionnaire. Besides including positive comments about the treatment and care delivered by the team at the Breast Cancer Center, these remarks also addressed shortcomings in the fields of psycho-oncologic care to support relatives and children and a lack of options to engage in physical exercise. Patients under adjuvant endocrine therapy used the opportunity to report their experiences. The comments also included suggestions to improve the brochure of the Breast Cancer Center. The material should provide more information about side effects of radiation therapy, including recommendations to prevent skin and scar changes, and give advice for the prevention of lymph edema. A total of 180 patients commented on the question about how to be contacted by the Breast Cancer Center for patient educational sessions; $68 \%$ of the respondents wished to receive a personal invitation.

\section{Discussion}

One of the main responsibilities of a $\mathrm{BCN}$ is to support breast cancer patients in understanding their disease by providing information on medical issues in a language that patients will understand. To perform this role, BCNs need to have special communication skills. Thus BCN training needs to focus on accurate, comprehensible communication using plain nonmedical language based on empathetic interaction to meet the needs of the patients.

The BCN's role within the multidisciplinary Breast Cancer Center team is perceived as that of a mediator between the different members of the health care team and the patient. This holds particularly true for the consultation and information offered by the BCN to complement the patient's contact with the physicians. BCN contact can improve the hospital organizational climate due to the altered patients' perception of physicians' communication [8]. The time available to talk to a doctor is limited and scheduled in a hospital setting within the framework of ward rounds, senior physician case presentations, and specialist consultation hours. In contrast, contacting a $\mathrm{BCN}$ represents a low-threshold service that can be provided with much greater flexibility and fewer time restraints.

It should be noted that the BCN's office in the hospital is right on the ward next to the patient rooms. The initial contact is made by the BCN. She goes to see the new patient, introduces herself, and leaves her business card with a phone number together with a flyer explaining her role and competencies and how and when to get in touch with her. Patients are thus enabled to contact the BCN according to their own needs. 'I felt very comfortable and someone was available whenever I felt the need to talk.' The comments of the respondents indicate that the support given by the $\mathrm{BCN}$ was not only needed immediately after the diagnosis but throughout the treatment process. The BCN serves as a guide within the medical system and in the continuum of care for the individual breast cancer patient and has a coordinating function. For example, she is responsible for contacting social services or transition management services, and she makes appointments for examinations, explains treatment plans and offers assistance for patients participating in clinical trials.

The support offered by the BCN is not limited to the patient's stay at the hospital. It encompasses the continuum of care across the sectors of health services, especially as all patients face further ambulatory care. Thus, the $\mathrm{BCN}$ remains as the contact person during the phase of radiation or chemotherapy and even follow-up care. 'The Breast Care Nurse was and still is a valuable help for me, she is the person to contact regarding important questions'.

The EORTC-QLQ-C30 questionnaire is an internationally validated and accepted assessment tool to measure overall health status and quality of life. For the purposes of this study, 
2 questions were used to compute the global quality of life score. The mean global quality of life score for women having contact with the $\mathrm{BCN}$ was 66.3 ; the mean score for the group without any contact was 62.5. Women who had been supported by a $\mathrm{BCN}$ had a significantly better post-discharge quality of life up to 1 year after leaving hospital than patients without any such contact. Particularly the scores of patients who did not have any contact with a $\mathrm{BCN}$ are comparable with the figures given in the literature (Klinkhammer-Schalke et al. [9] mean score 61.5; Kerr et al. [10] mean score 63.7). The mean scores of patients who had contact with a BCN, on the other hand, are more consistent with the mean scores in the general female population (range 63.7-69.7) determined by Schwarz et al. [11]. This observation needs to be verified because we did not use the entire questionnaire. A different study design would be needed to test the hypothesis of a possible causal relationship.

Women without BCN contact had less information about hospital procedures and their treatment plan, did not receive the information material as often as women with contact to a $\mathrm{BCN}$, and had less knowledge about their own tumor hormone receptor status. The study provides evidence that endocrine medication adherence correlates with the knowledge about one's personal positive tumor hormone receptor status. Moreover, it was shown that, in terms of communication and information, contact with the $\mathrm{BCN}$ contributed significantly to the compliance with the medication regimen. One of the most important findings of this study is the $30 \%$ difference in compliance found between women with contact versus those without any contact with a BCN. Given the importance of adjuvant endocrine therapy in the successful treatment of breast cancer, non-compliance has a detrimental effect since it lowers a patient's odds of survival. Furthermore, the burden of recurrent disease lowers patients' quality of life and has an overall impact on health costs. A total of $70 \%$ of breast cancer patients are eligible for adjuvant endocrine treatment. Therefore, adherence to standard guideline recommendations in breast cancer care is an important issue of health services research $[12,13]$. A high rate of non-compliance, or rather poor medication adherence, has already been demonstrated for women receiving routine cancer care outside clinical trials $[14,15]$. It has not been clarified yet which kind of support is needed to assist patients undergoing adjuvant therapy. The present results indicate that the services offered by a $\mathrm{BCN}$ can contribute to improve medication adherence. A further study would be needed to test this hypothesis.

\section{Limitations of the Present Study}

The study is retrospective and lacks a prospective randomized design. In the study, only $17 \%$ of the patients reported that they had not consulted a BCN. It is conceivable that women who had contact with a BCN, but also those without any such contact, differ with regard to various other influencing factors that may not have been addressed in the study. Other reasons for patients not contacting a BCN could be advanced disease or comorbidities. The study only elicited the subjective point of view of patients responding to the written survey. Socially desirable behavior represents a major bias that is associated with over- and underreporting. The survey was conducted at a single center. It is possible that structural aspects and organizational factors exist which would generate different results at other Breast Cancer Centers, meaning that the findings would not be transferable. Since it was based on the written comments and suggestions submitted by the patients, the qualitative assessment of the BCN's role was not done systematically and is limited to the spontaneous remarks made by patients. However, it is important to note that the study's quantitative and qualitative components complement each other. The findings demonstrate an advantage for the provision of care and support by a $\mathrm{BCN}$.

\section{Conclusion}

The study permits the conclusion that BCNs play an important and special role in breast cancer patient care at a Breast Cancer Center and have a positive impact on patients. Therefore, strengthening the role of BCNs by promoting a defined, qualified, and accepted continuing education program for specialized nursing is an important objective. Conduction of the study in multiple centers would help to assess the importance of the BCN and her value for the patients and their needs. Structural aspects of different centers regarding the job description of the BCN could be evaluated, compared, and in the long term probably improved.

\section{Acknowledgement}

We are thankful to all patients who participated in the study. We thank Andrea Rost at the Breast Cancer Center for secretarial help.

\section{Disclosure Statement}

The study was funded by an unrestricted grant from Novartis Pharma GmbH Oncology, Germany. The funding body had no role in the study design, data collection, analysis, interpretation, or writing of the report. 


\section{References}

1 Albert U, Wagner U, Kalder M: Breast centers in Germany. Breast Care 2009;4:225-230.

2 National Breast Cancer Centre: Specialist Breast Nurse Competency Standards and Associated Educational Requirements, 1st ed. Camperdown, NSW, National Breast Cancer Centre, 2005.

$\checkmark 3$ Catalotti L, de Wolf C, Holland R, Marotti L, Perry N, Redmond K, Rosselli Del Turco M, Rijken H, Kearney N, Ellis I, Di Leo A, Noel A, Andersson M, Audretsch W, Bjurstam N, Blamy R, Blichert-Toff M, Bosmans H, Burch A, Bussolati G, Christiaens M, Colleoni M, Cserni G, Cufer T, Cush S, Damilakis J, Drijkoningen M, Ellis P, Foubert J, Gambuccini M, Gentile E, Guedea F, Hendricks J, Jakesz R, Jassem J, Jereczek-Fossa B, Laird O, Lartigau E, Mattheiern W, O'Higgens N, Penney E, Rainsbury D, Rutgers E, Smola M, Van Limbergen E, von Schmitten K, Wells C, Wilson R, EUSOMA: Guidelines on the standards for the training of specialised health professionals dealing with breast cancer. Eur J Cancer 2007:43:660-675.

4 Eicher M, Marquard S: EONS Post-Basic Curriculum for Breast Cancer Nursing; Lehrbuch für Breast Care Nurses, Pflegende und weitere $\mathrm{Ge}$ sundheitsberufe. Bern, Hans Huber Verlag, 2008.
5 The American Association for Public Opinion Research: Standard Definitions: Final Dispositions of Case Code and Outcome Rates for Surveys, 5th ed. Lenexa, KS, AAPOR, 2008.

6 Fayers P, Aaronson N, Bjordal K, Groenvold M, Curran D, Bottomley A: EORTC QLQ-C30 Scoring Manual, 3rd ed. Brussels, EORTC Study Group on Quality of Life, 2001.

7 Scheffler H, Meulemann H, Dittrich W, Wenzel $\mathrm{O}$ : Erklärung für das Gebiet der Bundesrepublik Deutschland zum ICC/ESOMAR Internationalen Kodex für die Markt- und Sozialforschung. ADM Arbeitskreis Deutscher Markt- und Sozialforschungsinstitute e. V., 2008, pp. 1-2.

8 Kowalski C, Nitzsche A, Scheibler F, Steffen P, Albert U, Pfaff H: Breast cancer patients' trust in physicians: the impact of patients perception of physicians' communication behaviors and hospital organizational climate. Patient Educ Couns 2009;77:344-348.

$\checkmark 9$ Klinkhammer-Schalke M, Koller M, Ehret C, Steigner B, Ernst B, Wyatt J, Hofstädter F, Lorenz $\mathrm{W}$ : Implementing a system of quality of life diagnosis and therapy for breast cancer patients: results of an exploratory trial as a prerequisite for a subsequent RCT. Br J Cancer 2008;99:415-422.
10 Kerr J, Engel J, Schlesinger-Raab A, Sauer H, Hölzel D: Communication, quality of life and age: result of a 5-year prospective study in breast cancer patients. Ann Oncol 2003;14:421-427.

11 Schwarz R, Hinz A: Reference data for the quality of life questionnaire EORTC QLQ-C30 in the general German population. Eur J Cancer 2001;37:1345-1351.

12 Jackisch C, Untch M, Chatsiproios D, Lamparter C, Overkamp F, Lichtenegger W, Rönsberg W, Thomssen C, von Minckwintz G, Albert U: Adherence to treatment guidelines in breast cancer care - a retrospective analysis of the 'Organgruppe Mamma der Arbeitsgemeinschaft Gynaekologische Onkologie'. Breast Care 2008;3:87-92.

13 Pfaff H, Albert U, Bornemann R, Ernstmann N, Gostomzyk J, Gottwik M, Heller G, Höhmann U, Karbach U, Ommen O, Wirtz M: Methoden für die organisationsbezogene Versorgungsforschung. Gesundheitswesen 2009;71:777-790.

14 Ziller V, Kalder M, Albert U, Hozlhauer W, Ziller M, Wagner U, Hadji P: Adherence to adjuvant endocrine therapy in postmenopausal women with breast cancer. Ann Oncol 2009;20:431-436.

15 Hadji P: Improving compliance and persistence to adjuvant tamoxifen and aromatase inhibitor therapy. Crit Rev Oncol Hematol 2010;73:156-166. 